\title{
PSYCHOLOGICAL PECULIARITIES OF TOLERANCE OF UKRAINIAN AND POLISH STUDENTS: A COMPARATIVE ANALYSIS
}

\author{
Ihor D. Pasichnyk, Eduard M. Balashow \\ National University of Ostroh Academy, Ukraine \\ E-mail: ihor.pasichnyk@oa.edu.ua, eduard.balahov@oa.edu.ua
}

\begin{abstract}
The research reported here presents the theoretical aspects of the concept of tolerance of the academic youth, which is considered as a component of intercultural competence. The attitude of the students towards the people from other cultures and the level of their readiness to accept them are characterized. The influence of the surrounding socio-cultural environment on the development of ethnical and social tolerance is analysed. Moreover, the tolerance is viewed as a feature of the students' character. It was found out that a low level of ethnic tolerance prevails in 30.0\% of the Ukrainian students, which means that they demonstrate considerably lower tolerance towards other ethnic groups than Polish students. The indicators of moderate and high level of Polish students comprise $93.3 \%$ that means that they are far more willing to interact with other ethnic groups and the representatives of the socio-cultural environment if compared to the Ukrainian students (63.3\%), although the indicators of high and moderate level of the ethnic tolerance of Ukrainians are fairly high. The comparative results of the empirical research of ethnical, social tolerance and the tolerance as a feature of character of the Polish and Ukrainian students are specified. The important role of a higher educational establishment in the development of tolerance as a value in the modern multicultural and multi-ethnic societies is emphasized.
\end{abstract}

Key words: ethnic tolerance, index of tolerance, intercultural competence, intercultural tolerance, social tolerance.

\section{Introduction}

Today the youth more often works and communicates across the borders of the countries and continents. Foreigners join teams; students go abroad for pursuing international projects working internationally, thus more frequently delving into foreign cultures and experiencing various ways of thinking and behaviour. They do not always realize the nature of the differences they face and their influence on the quality of cooperation or the challenges, which may occur. The key to understanding the diversity in the multicultural world is to accept the fact that everyone offers some kind of a cultural programme acquired in their lifetime. One of the most recent studies in the field of social psychology emphasises that the culture in which we live is a universal system of values, which affects the perception, judgment and patterns of behaviour of the members of the group, society or organization. At the same time, it provides the definition for their identification with a group and its members (Thomas, 2003).

Culture is an important prism, which is peculiar for the occurrence of problems with one's 
acceptance of the attitudes, patterns of behaviour, ways of communication, thinking and reacting, which differ from the one to which they are accustomed. It reinforces the hypothesis that culture is a concept that relates not only to the regional or national culture or to ethnic minority, but has broader content.

Students nowadays strive for perfection in every sphere of their lives. The prevalence of mass culture and the access to mass media influence people's desire to live according to a certain stereotype or scheme. The youth is particularly susceptible to the trends and norms proposed by a social lifestyle. If a person does not meet those norms, they might feel rejected by the society. Each society should tolerate the desires of individuals and guarantee inclusiveness of every person as it is one of the basic needs. Therefore, the aim of the present research was to identify and compare the levels of tolerance that Polish and Ukrainian students have in the context of mobility, analyse multicultural, ethnic and social aspects of the process, define the main factors, which affect their views, and determine the influence of the surrounding social and cultural environment on their levels of tolerance.

In general terms, students' mobility requires from the young people to be culturally aware and to have an orientation in the multicultural diversity of a rapidly growing and expanding world. It is extremely important, then, to develop intercultural competence, which is seen as ability to notice, and respect cultural diversity and accept the factors that affect their perception, evaluation, feelings and behaviour (Thomas, 2003). Moreover, it is the ability to use them in the sense of mutual adjustment that ranges from tolerance to incompatibility to the development of synergetic forms of cooperation and patterns of interpretation of the surrounding social and cultural environment. By definition, intercultural competence is an essential element of modern organizations, which enhances one's elasticity while in contact with the different patterns of behaviour and communication styles.

Competences can be developed in several areas such as cognitive (knowledge), affective (skills including communication) and behavioural (attitudes). The simplest for assimilation is knowledge about the forms of behaviour. Intercultural competence development is an exploration of knowledge about one's own personality, such as norms and values, which determine the vision and evaluation of the norms that differ from the person's. The last sphere of the development of intercultural competence, specifically among the University students, is the affective or emotional level. This affects the skills of dealing with the stress, which appears in the intercultural contacts, including intercultural tolerance.

Tolerance as a phenomenon refers to many areas of social life. The social coexistence constantly requires from a personality the categorization of the reality objects in which they live. Categorization of the social reality and its classification finds its realisation in the attitudes towards many social trends, especially in modern Europe, which has become a place of racial, ethnic and cultural mixing. This variety related to the minorities grants the social life with the outlook of tolerance or discrimination depending on the situation whether the minority gains approval in the society or experiences separation and marginalization. Therefore, striving for tolerance arising from a sense of coexistence is a task for modern psychology.

Etymologically the word "tolerance" comes from Latin and means withstanding, indulgence, compassion, showing patience and understanding. Already at the etymological level, we are introduced in such aspect of tolerance, as tolerance is something that we permit.

The term "tolerance" is widely used for determination of compassion to other people's viewpoints and behaviours which differ from our own and those with which we disagree (Bozhovych, 1995).

In psychological context tolerance is defined as:

a) Attitude or behaviour that is illustrated in one's ability to respect the right of others to hold their own believes and types of behaviour, different from one's own and even contradictory to those;

b) Ability of the organism to withstand the negative impact of the environmental conditions without significant negative consequences (Winkler, 2008).

In the context of the current paper, tolerance is understood as an indulgence and understanding of other people's opinions, believes or deeds, even though they differ from what is considered to be 
correct or appropriate. Tolerating means enduring and patience (Tytarenko, 2003). Furthermore, Vol. 10, No. 1, 2016

tolerance is seen as recognition of the other people's right to have their own viewpoints, different from those of the evaluator, though not including anti-humanistic or criminal ideas can be seen. Intellectual tolerance means respect to other people's points of view, which is expressed in allowing them to speak. Moral tolerance means that different lifestyles, attitudes and norms are justified while maintaining elementary moral norms. Religious tolerance is understood as a right to accept or reject the beliefs or practices postulated by the various religions (Magala, 2011).

In theory, tolerance is an open, objective and respectful attitude towards the different attitudes, behaviours and characteristics of another person. In social, cultural and religious sense, tolerance and tolerating are used in describing the "tolerant" (or respectful) attitudes towards the group practices, which may be disapproved by those who are in majority.

Tolerance, in practice, indicates support of the attitudes, which are opposed to ethnic, racial or religious discrimination. Intolerance might be used for describing the discriminative practices or behaviours. Although the word "tolerance" appeared as the word referring to religious tolerance towards the religious minority arising from reformation that word up until now is commonly used for describing a larger number of the events related openness or respectfulness towards other attitudes, groups of viewpoints, which might differ from the viewpoint of the majority.

- Tolerance does not mean acceptance of somebody's behaviour or points of view. Contrary, tolerance is the respect of someone's behaviour or views.

- Tolerance is the attitude, which allows open discussion. Without this attitude, the discussion would be turned into a simple altercation or lead to aggression.

- Tolerance does not have limits as it applies to the attitudes, which are opposed to tolerance.

The distinction between a positive and negative tolerance should be made. Negative tolerance means not opposing oneself to individuals or groups. The reasons of such an attitude can be found in the desire of not violating the other's rights of freedom of acting and thinking or not perceiving the negative consequences of those actions. Refraining from the interference in pejorative behaviour can mean either indifference to the events or the desire to coexist in harmony with the environment. As Maria Ossowska notes, there is no way to speak about tolerance when, trying not to make enemies, we do not try to oppose the behaviour unacceptable for us. Tolerance therefore does not mean full acceptance of the views and actions crossing the limits of the rules and norms set by the society, thus crossing the borders of the social acceptance (Ossowska, 1983).

While analysing the attributes of positive tolerance, Maria Ossowska proves that it is an ability to respect the ideas and opinions different from one's own, arise from the kindness, and respect to the person expressing them. Respect towards another person arises from the belief that a man is a unique and dignified being who has the right to express their opinion towards alternative evaluations and attitudes to free activities. It means that the term 'tolerance' is ambivalent which means it has both positive (respect and recognition of human right to diversity) and negative signs, expressed by indifference that can be misread as an acceptance of diversity (Ossowska, 1983).

In the discussion about tolerance one should distinguish two scopes of its understanding and interpretation, such as narrow and wide. A narrow scope considers tolerance based on its external characteristics, which describe lack of opposition to the views, and actions represented by the person or society. A wide scope refers to the psychological mechanisms of this phenomenon.

Despite the multitude of interpretations of the phenomenon of tolerance, it can be understood as one's attitude. Therefore, tolerance may be and should be considered as the attitude comprising the cognitive, motivational, emotional and behavioural components, which are the exponent of the person's attitudes and behaviours towards the individual, objects to whom they want to be tolerant. Besides, considering tolerant attitudes as the ideas or thoughts, they may be determined as fair and actual exponents of attitude. Emotional attitude, knowledge and declared behaviour, which are contained in attitude, influence the strength of the attitude of a mature personality.

According to the accepted diversity of attitudes it can be assumed that a tolerant attitude is the one in which a pejorative evaluation is combined with a lack of willingness to consider someone in a negative way. Therefore, tolerance is the attitude in which the emotional and behavioural aspects 
take the opposite meanings. The strength of connection of the components might be considered as it testifies the indifferent tolerance attitude. The indifferent tolerance attitude may be easily observed in modern society. Lack of knowledge about minorities, together with a negative emotional attitude, does not restrict a declaration of a positive behaviour towards them. People always want to show themselves in the best possible way. Their positive self-presentation to "others" generates attitudes and creates new approach, indifferent in varying intensity.

\section{Aims and Hypotheses}

The present research aims to assess and describe the students' attitudes towards people from other cultures. A further goal was to compare the influence of the surrounding socio-cultural environment on the Polish and Ukrainian students' view of tolerance. Differences in levels of the students' general, ethnic, social tolerance and tolerance as a feature of character between the countries were also explored.

$\mathrm{H}_{1}$. High and moderate level of attitude towards the representatives of another culture should be higher among the Polish students compared to the Ukrainian peers. As far as gender differences are concerned, the available evidence is inconsistent.

$\mathrm{H}_{2}$. The Polish students' readiness to accept people from other cultures in their own surrounding is expected to be higher among the Polish students. This hypothesis was partly based on findings of the research conducted in Poland (Sarosiek et al. 2014; Buchowski \& Chlewińska 2010: Golebiowska 2014). The results of the research among the Ukrainian students lacked recent data to advance a strong hypothesis on these types of tolerance in this country.

$\mathrm{H}_{3}$. It was expected that surrounding social and cultural environment in Poland positively relates to the students' general, ethnic and social tolerance and creation of intercultural competence and "positive tolerance" towards appreciating the diversity of others (Szacki 2000; Spiewak 2000; Ambrosiewicz-Jakobs 2003).

It can be summarized that differences across the nations were expected mostly in the forms general, ethnic and social tolerance, which should reflect the specificities of the sociocultural, political and religious systems of the countries. Particularly, the expectation was that, independently of the specific contexts, the role of tolerance exhibited in Poland should be much higher, which may be explained by the wave of short-lived enthusiasm for other countries which followed the opening of the borders and transformation of the country's political system (Mihulka 2008).

\section{Method of Research}

In line with the theoretical and experimental hypotheses, which were about the exploration and comparison of such issues as the Polish and Ukrainian students' attitudes towards the representatives of another culture, their readiness to accept people from other cultures in their own surrounding, and the influence of the surrounding social and cultural environment on their intercultural, ethnic and social tolerance, a sample of 128 respondents was selected.

For evaluation and comparison of the levels of tolerance, the respondents were randomly selected from the Jagiellonian University in Krakow (Poland) and the National University of Ostroh Academy in Ostroh (Ukraine). The research was conducted under the guidance of authors in September-December 2014 by the use of an interactive questionnaire on the web-page of Institute of Culture of Jagiellonian University in Krakow (http://ankiety.interaktywnie.com/ankieta/5315c6d381712/). The responses of the respondents were analysed by IBM SPSS Statistics 20.

The questionnaire was subjected to translation for guaranteeing the equivalent meaning of the items in the two different languages. The Ukrainian team translated the Ukrainian version of the questionnaire into Polish. The items and words were carefully checked by the principal researchers in each country for finding the correct equivalent terms and phrases.

Interviewees were asked to complete the questionnaire online in both countries. The trained researchers presented the questionnaire. The instruments were anonymous and the appropriate procedures were followed for obtaining the permission to the study in the 
Data collection took place in Autumn-Winter 2014. Polish participants were 60 young adults attending the Jagiellonian University in Kraków (Table 1). About $26.7 \%$ were male. Age ranged from 18 to 22 years $(M=19.6, S D=1.28)$. Socio-economic background of the students is mostly at average levels, similar to the students attending other Polish Universities, since the generally low costs of enrollment allows almost all youngsters to obtain a University degree.

Ukrainian participants were 68 students of the National University of Ostroh Academy. About $41.4 \%$ were male, and $58.8 \%$ were female. Age ranged from 17 to $23(M=21.4, S D=2.18)$.

\section{Table 1. Representation of Polish and Ukrainian respondents of the research (N (\%)).}

\begin{tabular}{|c|c|c|c|}
\hline & Poland & Ukraine & Total \\
\hline \multicolumn{4}{|l|}{ Gender } \\
\hline M & $16(26.7)$ & $28(41.2)$ & $44(34.4)$ \\
\hline $\mathrm{F}$ & 44 (73.3) & $40(58.8)$ & $84(65.6)$ \\
\hline \multicolumn{4}{|l|}{ Age } \\
\hline $17-19$ & 37 (61.7) & $16(23.5)$ & $53(41.4)$ \\
\hline $20-21$ & $11(18.3)$ & $19(28.0)$ & $30(23.4)$ \\
\hline$>21$ & $12(20.0)$ & $33(48.5)$ & $45(35.2)$ \\
\hline Total & $60(46.9)$ & $68(53.1)$ & $128(100.0)$ \\
\hline
\end{tabular}

Summarizing, the students involved in the research belong to two competitive Universities, which attract students from all over the respective country. A specific difference is that the free of charge of lower cost of education in Ukraine, compared to Poland, allows students from different socio-economic backgrounds to have a chance to attend the NUOA and receive a degree. The peculiar characteristics of the two national contexts should be helpful to draw attention to the social processes through which the different forms of tolerance may influence the students' intercultural competence.

\section{Research Instrument and Procedures}

The research was conducted with the use of individual standardized questionnaire. This allowed respondents to formulate their own assessments. Moreover, it provided the results to be used in both quantitative and qualitative analysis.

The material used in the experimental phase was an express-questionnaire (methodology „Index of Tolerance” by G. Soldatova, O. Kravtsova, O. Chuchlaiev, L. Shaigerova) (Soldatova et al. 2008). This methodology allowed for determining the level of tolerance (high, moderate, low), with the purpose to do quantitative analysis of tolerance to extract such scales as general, ethnic, social tolerance and tolerance as a feature of character.

Individual or group evaluation of the level of tolerance is done according to the following levels. Low level indicates high intolerance of a person and presence of intolerant features in relations to the surrounding people and socio-cultural environment. Moderate level is typical of people who combine both tolerant and intolerant features. In certain situations, they behave both tolerating and not tolerating that depends on the circumstances. Respondents with a high level of tolerance possessed the features of a tolerant person. At the same time, it is necessary to understand that if the level of tolerance is very high, it indicates blurring of the person's "tolerance limits", which may be associated with psychological infantilism and tendencies to indifference.

For qualitative analysis of the aspects of tolerance, the additional sub-scales were used. Subscale "Ethnic tolerance" reflects a person's attitude towards the representatives of other ethnic groups and their characteristics in the sphere of intercultural interaction. Sub-scale "Social tolerance" 
makes it possible to research tolerant and intolerant expressions regarding other social groups and people's attitude towards certain social processes. Sub-scale "Tolerance as a feature of character" explores the personal qualities and beliefs which largely define their attitude towards the surrounding socio-cultural environment.

\section{Results of Research}

Table 2 shows the received data concerning the levels of tolerance of Polish and Ukrainian sample.

Table 2. Levels of tolerance of Polish and Ukrainian students.

\begin{tabular}{ccccc}
\hline Type of tolerance & Students & $\begin{array}{c}\text { Low } \\
\text { level (\%) }\end{array}$ & $\begin{array}{c}\text { Moderate } \\
\text { level (\%) }\end{array}$ & $\begin{array}{c}\text { High level } \\
(\%)\end{array}$ \\
\hline \multirow{2}{*}{ General } & Ukrainian & 40 & 48.3 & 11.7 \\
& Polish & 8.3 & 70 & 21.7 \\
\multirow{2}{*}{ Ethnic } & Ukrainian & 36.7 & 55 & 8.3 \\
& Polish & 6.7 & 73.3 & 20 \\
\multirow{2}{*}{ Social } & Ukrainian & 35 & 51.7 & 13.3 \\
& Polish & 5 & 70 & 25 \\
& Ukrainian & 8.3 & 55 & 36.7 \\
& Polish & 5 & 63.3 & 31.7 \\
\hline
\end{tabular}

The reported results of the indicator of a general tolerance of Polish and Ukrainian students according to methodology „Index of Tolerance” are represented in Table 1 and Figure 1, ethnic tolerance is depicted in Figure 2, social tolerance is illustrated in Figure 3, while tolerance as a feature of character is presented in Figure 4.

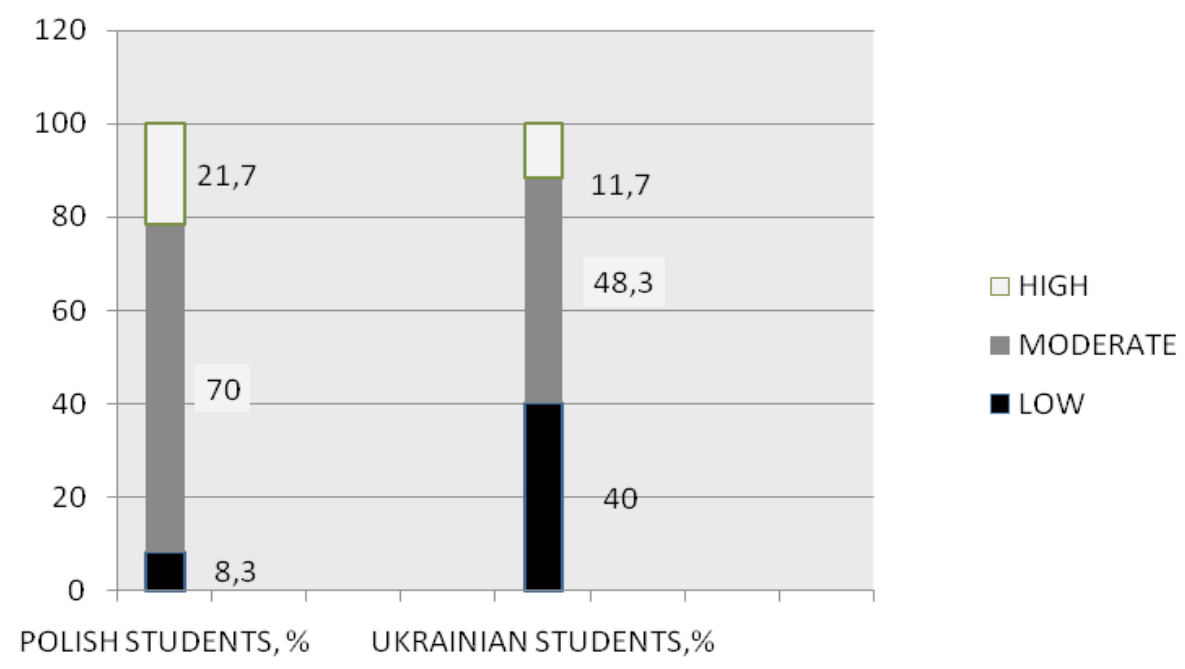

Figure 1: Level of indicator of general tolerance of Polish and Ukrainian students according to methodology „Index of tolerance”.

The Figure below gives a graphical representation of the indicators of ethnic tolerance of the respondents. A low level of ethnic tolerance prevails in $36.7 \%$ of the Ukrainian student, which means that they demonstrate considerably lower tolerance towards other ethnic groups than Polish students. The indicators of moderate and high level of Polish students in sum comprise $93.3 \%$, which 
means that they are far more willing to interact with other ethnic groups and the representatives of the socio-cultural environment if compared to the Ukrainian students (total 63.3\%), although the indicators of high and moderate level of the ethnic tolerance of Ukrainians are fairly high.

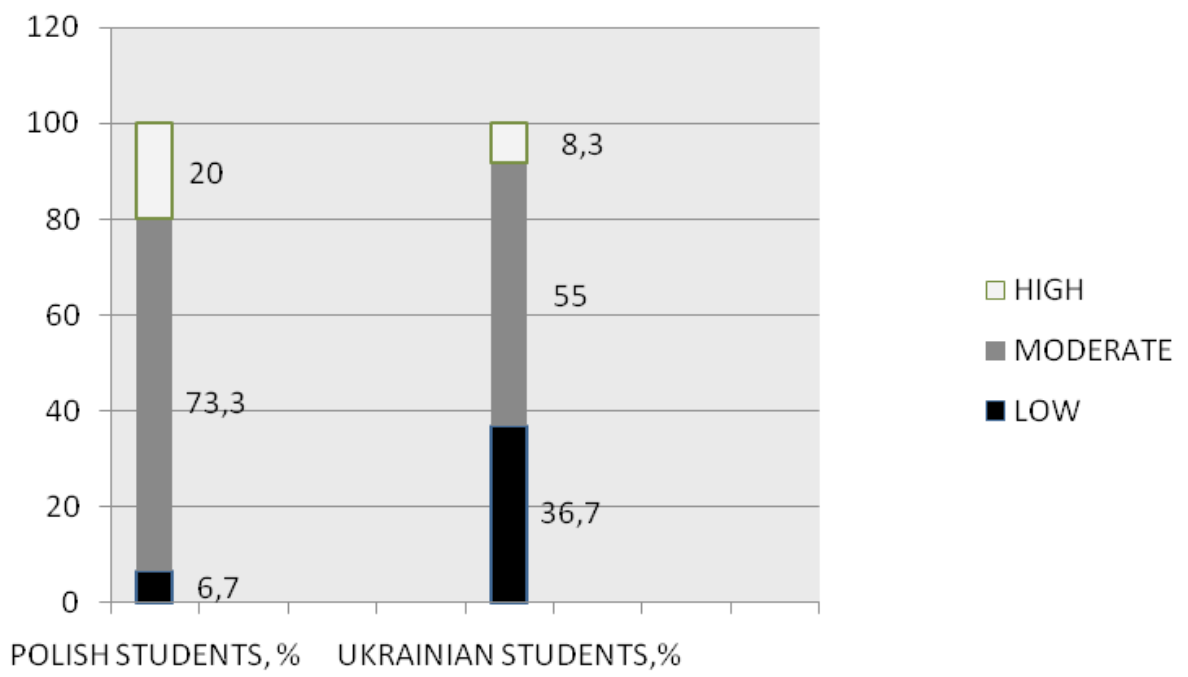

\section{Figure 2: Level of indicator of ethnic tolerance of Polish and Ukrainian students} according to methodology „Index of Tolerance”.

Social tolerance is a following indicator of this cognitive component (Figure 3). The empirical data of indicator of the social tolerance research proves that every fourth interviewed Polish student (25.0\%) has a high level of that type of tolerance, whereas only $13.3 \%$ of the Ukrainian students demonstrate this same level. Yet, $70.0 \%$ of the Polish students and $51.7 \%$ of the Ukrainian students have a moderate level of this type of tolerance respectively. This indicates that the Ukrainian students are less tolerant towards the different social groups and certain situations of deviant behaviour in the social processes. At the same time, every third Ukrainian student (35.0\%) has a low level of the social tolerance. The statistical data proves that the social problems and challenges of the surrounding socio-cultural environment have smaller importance for the Ukrainian students.

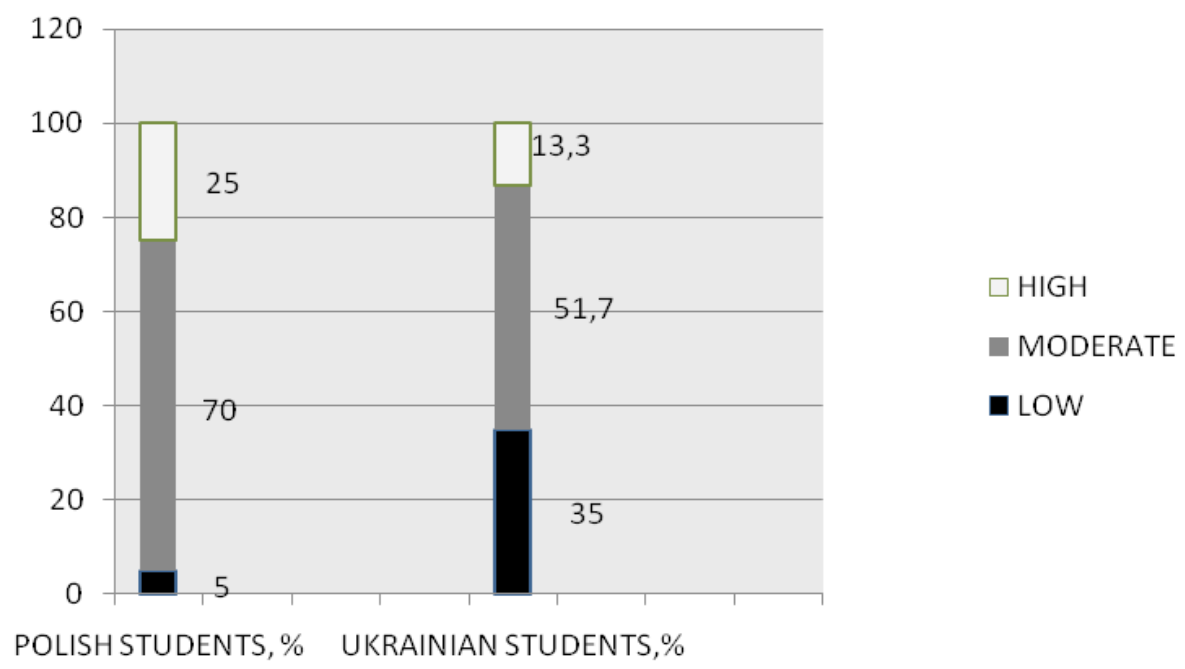

Figure 3: Level of indicator of social tolerance of Polish and Ukrainian students according to methodology „Index of Tolerance”. 
Figure 4 graphically represents the empirical indicators of the tolerance as a feature of character of the Polish and Ukrainian respondents.

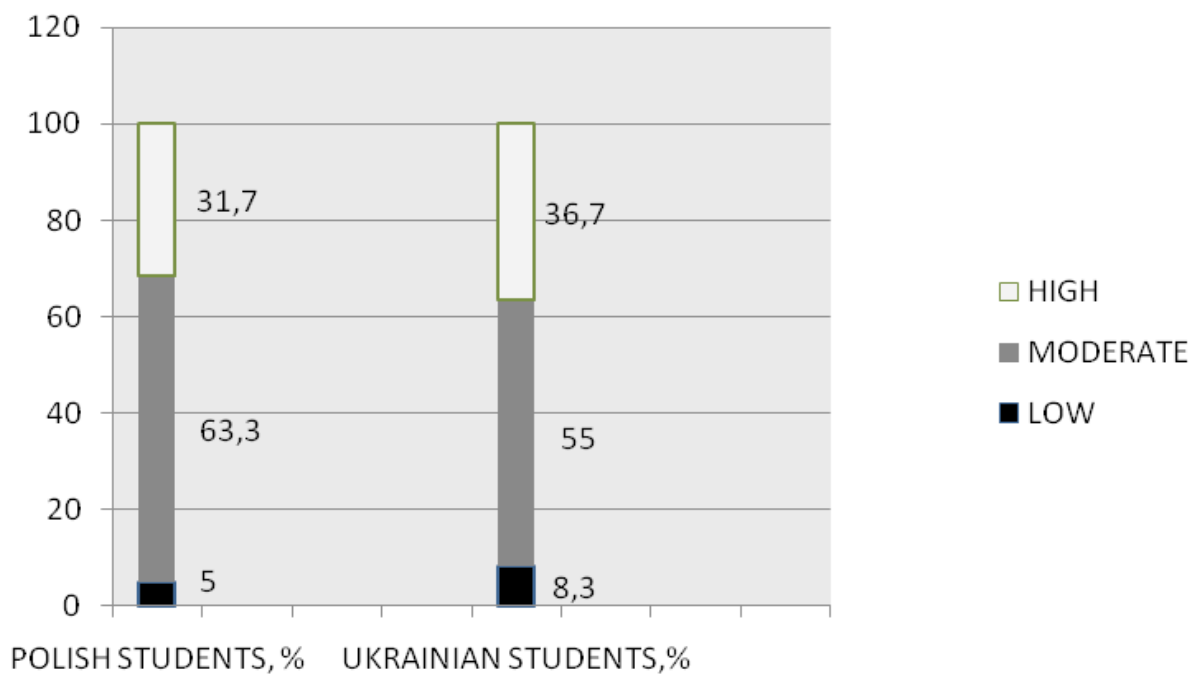

Figure 4: Level of indicator of tolerance as feature of character of Polish and Ukrainian students according to methodology "Index of Tolerance”.

It is easy to notice that over $5.0 \%$ of the Ukrainian respondents have a high level of this type of tolerance as compared to the Polish ones. 95.0\% of the Polish students and 91.7\% of the Ukrainians have high and moderate levels of tolerance as a feature of character, which means that both the Ukrainian and Polish students have fairly highly developed personal characteristics, beliefs and viewpoints. It determines their more tolerant attitude towards the surrounding socio-cultural environment of both Poland and Ukraine.

Table 3 shows correlation between the level of tolerance of the Polish and Ukrainian students (only alternatives "moderate" and "high" are reported)

Table 3. Correlation between the level of tolerance and nationality of students.

\begin{tabular}{|c|c|c|c|c|c|}
\hline Type of tolerance & Students & $\begin{array}{l}\text { Moderate } \\
\text { (N) }\end{array}$ & $\begin{array}{l}\text { High } \\
\text { (N) }\end{array}$ & $\begin{array}{c}\text { Pearson's } \\
\text { X2 }\end{array}$ & Cramér's V \\
\hline \multirow{2}{*}{ General } & Ukrainian & 29 & 7 & \multirow{2}{*}{$9,878^{*}$} & \multirow{2}{*}{$0,374^{*}$} \\
\hline & Polish & 42 & 13 & & \\
\hline \multirow{2}{*}{ Ethnic } & Ukrainian & 33 & 5 & \multirow{2}{*}{$15,405^{* *}$} & \multirow{2}{*}{$0,422^{* *}$} \\
\hline & Polish & 44 & 12 & & \\
\hline \multirow{2}{*}{ Social } & Ukrainian & 31 & 8 & \multirow{2}{*}{$8,906^{*}$} & \multirow{2}{*}{$0,296^{*}$} \\
\hline & Polish & 42 & 15 & & \\
\hline \multirow{2}{*}{ Tolerance as feature of character } & Ukrainian & 33 & 22 & \multirow{2}{*}{5,137} & \multirow{2}{*}{0,166} \\
\hline & Polish & 38 & 19 & & \\
\hline
\end{tabular}

${ }^{*} p<0,05{ }^{* *} p<0,01{ }^{* * *} p<0,001$

Pearson's $\chi^{2}$ shows that for the moderate and high levels of general, social and ethnic tolerance, certain correlation is found mostly for the Polish sample. However, we cannot ascertain a strong correlation between these scales and nationality according to the Cramer's V, as the correlation is moderate for general tolerance $(\mathrm{V}=0.374, p<0.05)$ and ethnic tolerance $(0,422 ; p<0.01)$, and low for social tolerance $(0.296, p<0.05)$. 
No significant differences were found in the relations between tolerance as a feature of character and nationality of students.

\section{Discussion}

The research presented in the topic in this paper investigated a relatively understudied topic in a sample of university students: comparative research of tolerance across two different nations: Poland and Ukraine. The phenomenon of tolerance is gaining increasing attention on the scientific literature. There are different approaches to understanding the meaning of tolerance in the psychological science. In the light of the Ukrainian age and pedagogical psychology, tolerance is considered through a prism of a personality development and necessary pedagogical impact on that development. V. Moskalenko believes that tolerance is an impartiality in assessment of different events and ideas, especially patience towards the peculiarities of people, their ability to ensure the communicative competence and consensus (Moskalenko, 2008). Tolerance as a basis of effective communicative interaction is analysed in the works of V. Boyko (1996). Moral and ethical foundations, features of character and life experience contribute to the development of general tolerance which determines other forms of communicative tolerance. S. Bratchenko considers tolerance as a factor of effective interpersonal interaction (Bratchenko, 2001). A definition of ethnic tolerance is analysed in works of N. Lebedeva, who concludes that ethnic tolerance is fundamental guarantee of peace in a society (Lebedeva, 1999). It is very important to analyse a cognitive (knowledge about another culture), activity (intercultural communication) and emotional-volitional (emotions, tolerance, empathy) components of intercultural tolerance (Kovalchuk, 2010).

The phenomenon of tolerance has been considered crucially important in Polish psychological science. The former meaning of tolerance is close to the notion of 'negative tolerance' introduced by Ilia Lazari-Pawłowska (1984). The latter meaning of tolerance, often referred to as "positive tolerance", is used in a much broader sense. Jerzy Szacki (2000) defines it as an attitude of acceptance of others who may hold and advocate different views, and also follow lifestyles one personally does not approve of. Being tolerant means appreciating diversity and regarding it as a value in itself. "Positive tolerance", then, means not only an awareness of diversity, but also a positive attitude towards 'the other', an openness to 'the other' as well as willingness to respect and support diversity in others (Śpiewak, 2000). From the point of view of groups that are tolerated, the principle of tolerance is problematic. Acceptance would be a preferable term. As J. Ambrosewicz-Jacobs points out, "the attitude of tolerance comes from the individual rather than the state, but the community or the state is responsible for the fact of tolerance, that is, for ensuring that no one is victimized by intolerance" (2003).

Tolerance is regarded as one of the most important values defining European culture. It is believed that in the most highly developed, democratic and pluralistic societies, where individuals enjoy full civil liberties, where minorities have their equal rights and the protection of the state guaranteed, there are conditions conducive to tolerance. And yet, even in such open and liberal societies we may encounter blatant examples of racial prejudices and discrimination.

\section{Conclusions}

The findings of the present research suggest that the Polish students can be characterized as more tolerant and aware of cultural differences. They are more tolerant in relation to people from the different culture, have a higher level of general and ethnic tolerance $\left(\mathrm{H}_{1}\right)$.

Results also support the hypothesis concerning the Polish students' readiness to accept people from other cultures $\left(\mathrm{H}_{2}\right)$. Finally, as expected, the paper proves the hypothesis that surrounding social and cultural environment in Poland positively relates to the students' general, ethnic and social tolerance and creation of intercultural competence and "positive tolerance" towards appreciating the diversity of others $\left(\mathrm{H}_{3}\right)$. It can be concluded that such processes take place in the student environment in Poland, which is partly caused by the influence of the surrounding socio-cultural environment, openness of the joint European socio-cultural space and a greater degree of the in- 
tegration of Polish academic youth. This kind of influence is not so significant in Ukraine since a great influence of imperial propaganda of so-called "brotherly country" from the East is still felt. Especially that influence deepens in Ukraine in the light of the recent aggressive actions of Russia. Partially, it can be confirmed by the result of the research showing the lower level of general, ethnic and social tolerance of the Ukrainian students.

On the other hand, more Ukrainian students have a higher level of tolerance as a feature of character, which means they have a higher ability to actively cooperate with a surrounding sociocultural environment in crisis and problematic situations in order to renew their own psychological balance, have successful adaptation, avoid confrontation and develop positive relations with each other and the socio-cultural environment.

Overall, it is possible to conclude that the findings of the research support the positive association between tolerance and cognitive, motivational, emotional and behavioural components of the student's personality. The important role of higher educational institutions in the development of tolerance is emphasised for both nations. However, more research is needed to confirm this pattern in different groups and national contexts. This would help to further illuminate the mechanisms and processes underlying the phenomenon. Moreover, a closer look should be given to specific forms of the tolerance in the national context and practical implication of the results in both countries for the educational purposes.

In conclusion, it can be admitted that the evidence is promising and sheds light on an important phenomenon, having both theoretical and applied implication. Development of tolerance is one of the key characteristics of humanization of society and socio-cultural environment both in Poland and Ukraine. This conducted research proves that the proposed theoretical and practical achievements could find further practical use in education and upbringing of the students in higher educational institutions, and may be widely used in both countries by the social workers, psychologists, educators and the youth themselves for forming their aspects of intercultural competence.

\section{References}

Ambrosewicz-Jacobs, J. (2003). Me, us, them: Ethnic prejudices among youth and alternative methods of education. The case of Poland. Kraków: Universitas.

Bozhovych, L. (1995). Izrannye psihologicheskie raboty [Selected psychological works. Issues of formation of a personality]. Moscow: International Pedagogical Academy.

Boyko, V. (1996). Energiia emotsiy v komunikatsii [Energy of emotions in communication]. Moscow: Filin.

Bratchenko, S. (2001). Ekzestentsialnaiia psihologiia glubinnogo obshcheniia [Existential psychology of profound communication]. Moscow: Smysl.

Buchowski, M., \& Chlewińska, K. (2010). Tolerance and cultural diversity discourses in Poland. European University Institute, Robert Schuman Centre for Advanced Studies.

Fetiskin, N., Kozlov, V. \& Manuilov, G. (2002). Socio-psihologicheskaia diagnostika razvitia litchnosti i grup [Socio-psychological diagnostics of development of a personality and groups]. Moscow: Institute of Psychotherapy.

Golebiowska, E. (2014). The many faces of tolerance: Attitudes towards diversity in Poland. New York: Routhledge.

Hornostai, R., \& Tytarenko, T. (2001). Psihologiia lichnosti [Psychology of a personality]. Kyiv: Ruta.

Kovalchuk, I. (2010). Foreign language communicative culture as needed component of effective intercultural communication. Scientific Notes of the National University of Ostroh Academy. Series "Psychology and Pedagogy", 16.

Kuliutkin, Y., \& Sukhobskaia, H. (1996). Lichnost: vnutrenniy mir i samorealizatsiia [Personality. internal world and self-realization]. Saint-Petersburg: Piter.

Lazari-Pawłowska, I. (1984). Three definitions of tolerance. Studia Filozoficzne, 8.

Lebedeva, N. (1999).Vvedeniie v etnicheskuiu i kross-kulturnuyu psihologiiu [Introduction to ethnic and crosscultural psychology]. Moscow: Kluch. 
Magala, S. (2011). Intercultural competences. Kraków: Wolters Kluwer Polska.

Maksymenko, S., \& Pasichnyk, I. (2010). Role of cognitive and stylistic peculiarities of a personality in the process of education activity. Scientific Notes of the National University of Ostroh Academy. Series "Psychology and Pedagogy", 14.

Mihulka, D. (2008). Tolerance or acceptance - Ethnic attitudes in contemporary Poland: An analysis of empirical studies. 17th Annual Convention of the Global Awareness Society International, May 2008, San Francisco, CA, USA.

Moskalenko, V. (2008). Sotcialnaia psihologiia [Social psychology]. Kyiv: Tsentr uchbovoi literatury.

Ossowska, M. (1983). About a person, moral and science: Miscellanea. Warsaw: PWN.

Rakowska, A., \& Sitko-Lutek, A. (2000). Improvement of managerial competences. Warsaw: PWN.

Rębisz, S., \& Sikora, I. (2015). The main motivation of Ukrainian students who choose to study in Poland. Practice and Theory in Systems of Education, 10 (4).

Sarosiek, J., Długołędzka, K., Mazur, K. P., Van Damme-Ostapowicz, K., \& Krajewska-Kułak, E. (2014). Tolerance of the students at the medical university in Białystok for different race, language and religion. Archives of Physiotherapy and Global Research, 18 (1), 10-17.

Soldatova, G., Shaigerova, L., Prokofieva, T., \& Kravtsova, O. (2008). Psichodiagnostika tolerantnosti lichnosti [Psychodiagnostics of tolerance of a personality]. Moscow: Smysl.

Szacki, J. (2000). Entry for 'Tolerancja'. In: Internetowa encyclopedia PWN. Retrieved from http//: www. encyklopedia.wp.pl.

Śpiewak, P. (2000). Spór o Polskę. Warszawa: PWN.

Thomas, A. (2003). Interkulturelle Kompetenz - Grundlagen, Probleme und Konzepte. Paderborn: Erwägen Wissen Ethik- Streitforum für Erwägungskultur, 14, 137-228.

Tytarenko, T. (2003). Zhyttievyi shliah osobystosti: zseredyny ta zzovni povsiakdennogo zhyttia [Life path of a personality: Inside and outside of everydayness]. Kyiv: Lybid.

Winkler, R. (2008). Management of communication in culturally different organizations. Kraków: Wolters Kluwer Polska.

Advised by Tetiana M. Shyriaieva, National University of Ostroh Academy, Ukraine

Received: February 06, 2015

Accepted: May 20, 2016

\begin{tabular}{ll}
\hline Ihor D. Pasichnyk & $\begin{array}{l}\text { PhD., Professor, Rector of the National University of Ostroh Academy, } \\
\text { Seminar 2, 35800 Ostroh, Rivne region, Ukraine. } \\
\end{array}$ \\
E-mail: ihor.pasichnyk@oa.edu.ua
\end{tabular}

